\title{
VECTORS OF OCCUPATIONAL HEALTH DEVELOPMENT
}

\section{Burlakova I. A., Sheviakov O. V.}

\section{INTRODUCTION}

Social change in Ukraine requires a modern specialist of activity and responsibility, which characterize the value attitude to professional activity and one's own professional and personal development ${ }^{1}$.

There is a loss of established ideas about professional activity, through which the specialist determines himself and his place in society, that is, there is a crisis of professional formation at the level of self-consciousness, both as an individual person and within the generations. Sharp social changes, as well as the development of the system of mutual influence of cultural traditions, the strengthening of migration processes have led to increased subjective involvement in various real and virtual professional groups of specialists.

In these conditions the integrity and formation of the psychological structure of the professional health of the individual becomes of great significance.

The issue of health and professional health is the subject of research by many scholars, which leads to the presence of a large number of approaches to the interpretation of this phenomenon. In particular, the problems of preserving human health in modern conditions and peculiarities of its personalityprofessional formation, the specifics of life and professional development of the personality within the limits of ontogenetic research of problems of life selfrealization, its professional self-determination as a component of life development, motivational-adaptive content of professional activity, strategy the formation of a healthy lifestyle, medical pedagogical and psychological and pedagogical problems of the formation of a healthy lifestyle in youth, in particular the student. At the same time, existing approaches to the study of the phenomenon of professional health do not allow to analyze its structure as a holistic and complexly organized psychological education; operationalize the hierarchical model of professional health professionals ${ }^{2}$.

${ }^{1}$ Golovkova L.S., Sheviakov A.V., Golovkova A.E. Philosophical and sjciocultural dimensions of personality psychological. Antropological Measurements of Philosophical Research. 2018. Issue 14. P. 73-83.

2 Yevdokymova N., Sheviakov O., Koval I. at al. Psychologycal Provision of Processes Modernization of Metallurgical Production Management. International Journal of Recent Technology and Engineering. 2019. Issue 8 (4S). P. 115-121. 
Thus, there are currently unresolved problems in the field of professional health professionals, in particular the economic sphere of activity, and the unwillingness to highlight the socio-psychological foundations of the processes of its formation and preservation under the influence of global transformations of modern society and the development of the state ${ }^{3}$.

\section{Theoretical and methodological foundations of the study of the problem of occupational health of the individual}

It is found that the diversity of foreign studies in the field of occupational health is reduced to consideration of the following issues: stress in professional activity; physical (from work-related injuries to cardiovascular disease) and mental health (distress, burnout, depression); unhealthy lifestyle factors (smoking, alcohol and drugs); job satisfaction, work-life balance and rewards (salary, recognition, status, rewards prospects, etc.), impact of adverse workplace events on personal life and health, workplace safety (impact of work changes on occupational health), psychological effects of unemployment.

It is estimated that in national science there are different approaches to defining the concept of "occupational health", which is considered as: the property of the organism to preserve the set compensatory and protective mechanisms that ensure efficiency in the conditions of professional activity, the process of preserving and developing the regulatory properties of the organism, its physical, mental and social well-being; ability of the person to compensatory functions, dynamic state, which reflects the efficiency of the process of adaptation of the organism to the conditions of vital activity, integral characteristic of the functional state of the human body, multilevel, complex, systemic concept, which includes emotional, cognitive, behavioral aspects of personality, somatic, mental, social, existential levels, a certain level of characteristics of health of a specialist.

A categorical matrix of occupational health that combines emotional, behavioral and cognitive components is considered. It is established that the emotional component includes the range of experiences of the specialist, which arises in his professional activity and relates to adequate emotional response. The behavioral component includes features of the specialist's behavior, which contribute to its adaptation to changing environmental conditions and professional activity, as well as behavioral strategies based on health, lifestyle and working conditions. The cognitive component involves an adequate understanding of one's level of health based on

${ }^{3}$ Golovkova L.S., Sheviakov A.V., Golovkova A.E. Psychological provision of professional health of specialists of economic sphere. Review of transport economics and management. Issue 2(18). P. 90-99. 
knowledge of healthy lifestyles, including in fulfilling professional responsibilities, awareness of the role of health and its impact on life in general, and the success and effectiveness of professional activity, in particular, understanding major risk factors for the profession, as well as ways to preserve and promote occupational health.

The main directions of the study of the problem of occupational health, which are mostly pragmatic, are the development and implementation of programs for health promotion of specialists, elimination of negative effects of stress in the workplace. Occupational health promotion programs have been shown to achieve the following goals: prevention of the burn-out phenomenon; improvement of the moral and psychological climate in the team; improving productivity by improving the physical and mental health of professionals; reducing occupational injuries and the like. It is noted that in both foreign and domestic science, the diversity of approaches to preserving and promoting occupational health lies in the development of health management programs and includes information-diagnostic and rehabilitation practices. It is determined that occupational health is based on the following principles: reducing the negative impact of the occupational environment on the health of the specialist; taking into account the state of health and the contraindications to certain activities and professions in the process of professional selection; increasing the adaptive capacity of the individual to overcome the negative factors of the professional environment.

It is established that the problem of occupational health is an area of interdisciplinary research and its study is reduced to the issues of consistency of requirements of the professional environment and opportunities of the individual for successful and effective fulfillment of conditions of professional activity.

It is stated that the majority of studies on occupational health are devoted to the prevention of occupational diseases. At the same time, a much smaller number of theoretical and practical developments are aimed at its formation and strengthening, in particular for specialists in the economic sphere. The purpose of the article is to find a new solution to the problem of creating psychosocial foundations of occupational health of economic specialists from the standpoint of behavioral economics. Proposed conceptual model of professional health of specialists in the economic sphere; the analysis and generalization of the results of the research phase is carried out.

It is established that the professional health of specialists in the economic sphere is characterized by the following components: characteristics (social and personal); levels (physical, psychological, social); components (somaticmental health, social-psychological health, moral-ethical health).

It is found out that the social component is considered as a measure of working capacity, social adaptive offer, activity of a specialist to being; 
personal component - as a strategy of his life, level of personal competence; physical level - as well-being, frequency of diseases, efficiency, activity and energy potential; psychological level - as characteristics of attention and memory, emotional well-being, stress resistance, features of behavior aimed at health promotion, absence of signs of occupational deformities; social level - as a professional motivation, job satisfaction, professional demand, focus on professional development, social and psychological adaptation to the professional environment. Somatic-mental health has been found to be defined as the optimal relationship between the mental and physiological processes of the individual in the context of professional activity; sociopsychological health - as features of interaction in the system of "professional-professional environment", which are determined through adequate perception of social reality, adaptation to the professional environment, focus on public affairs, altruism, responsibility, etc.; moral and ethical health - as a type of occupational health characterized by compliance with the norms, principles, code or statute of the profession without harming the overall health.

An algorithm for evaluating the occupational health of specialists in the economic sphere has been developed, aimed at solving the following tasks: humanization of entertainment education through the acquisition of moral values by specialists in the economic sphere; building a culture of health based on positive attitudes and skills, and lifestyle adjustment; the quality of education received by specialists in the economic sphere; studying the mechanisms of adaptation to professional activity, preservation and promotion of health in the dynamics of vocational training; hygienic examination of the professional process; organization of cultural, mass, sports and health work on the basis of the principles of accessibility, systematic, differentiated and innovative, organization of systematic medical examinations.

The main symptoms of professional health disorders in the economic sphere have been identified, which include negative subjective status, which is manifested by a deterioration of state of health, a decrease in the level of professional activity, a decrease in the interest in innovations, their support; instability of emotional sphere; reduced or complete disability; decrease in the volume and degree of mobilization of functional reserves (rapid fatigue, decrease in attention, refusal of active training methods that require significant psycho-physiological costs, long period of involvement in the activity; reduction of portability of increased physical and mental load); manifestations of psychological violence in the professional environment (self-affirmation at the expense of others), manifested in open rejection and constant criticism; humiliation of human dignity; threats; making demands that are not appropriate to the age or capabilities of the specialist. 
The influence of stressors on the occupational health of specialists in the economic sphere, related to the content of professional activity, its organization; ways to build a professional career; corporate relationships; non-organizational sources of stress.

The determinants and factors influencing the professional activity and its organization in the economic sphere are determined. Emphasis is placed on the specifics of the organization of work, in particular, its irregularity (excessive overload, strenuous mental activity or a clear underload in the volume of work), working conditions (organization of workplace, quality of equipment); uniformity of work performed; change of duration or working conditions, inconvenience of working hours, work at weekends; work not provided for in this position, increased responsibility; difficulties in the activities being performed, including incompleteness of required information, shortage of time, increased requirements for speed of action; the situation of uncertainty; concern about the consequences of possible wrongdoing; the need to make urgent responsible decisions; disorders of biological rhythms (including sleep disorders), unfavorable functional state of the organism in the course of performing activities; novelty, reorganization at work.

The professional group of working with internal clients (administrators, assistants, managers) was 240 people: 130 men and 110 women; A professional team working with external clients (sales managers, customer service managers, consultants) - 220 people: 124 men and 96 women; and in the professional group of executives (at different levels - from the head of the department to the general manager of a medium-sized business) - there were 170 participants -92 men and 78 women.

It is determined that managers are more focused on the past and present, and those who work with internal clients - for the future $(p \leq 0,01)$. We believe that this can be explained: in most cases, leaders have a rich life experience, a successful career that they remember with pride; in this their position implies an active participation in the life of their organization, decision-making; the future worries them to a lesser extent than other professionals who can only predict a successful career in the future. With regard to the high level of personality-situational anti-capability in the field of economic affairs, especially those who work with external clients $(\mathrm{p} \leq 0,01)$, we consider it logical: specialists who work with people are well aware of their possible reactions, actions, actions and can foresee them. Specialists working with external clients have to contact every day with a lot of new people, due to which their experience of communication is more diverse and large.

It is revealed that specialists working with internal clients are more inclined to solve difficult situations through strategic planning and 
emocional support search, and those who work with external clients through proactive and reflective overcoming $(p \leq 0.01)$. We believe that professionals who work with external clients are often in contact with new people, they have to deal with conflict situations, work in a constantly changing environment, and if possible, they seek to estimate potential risks and potential problems; and specialists working with internal customers often plan their future, and seek support from more experienced and relevant individuals.

A number of gender differences have been identified: men have higher rates at all three levels of occupational health than women $(p \leq 0.05)$, except for health status (by degree of predisposition to diseases). It can be assumed that men are more likely to take leadership positions than women and have time and resources to maintain their health; Men pay less attention to manifestations of diseases and various ailments, therefore, in the questionnaire, self-esteem high marks about health and other indicators of professional health.

It is established that men have a more pronounced temporal orientation "Future", and women - "Transcendental future" ( $p \leq 0.05)$; women have a more pronounced tendency to emotional immersion in today's events, and in men - to structuring current events and planning future events $(p \leq 0.05)$. In our opinion, this corresponds to certain facts and gender stereotypes: men are more focused and able to structure events that occur, and women are more inclined to religious ceremonies, more often turn to astrologers, horoscopes, search for certain "signs" given by the universe, etc. Men have a more pronounced spatial and temporal anti-smoking capacity than women $(p \leq 0.05)$. Men have a greater tendency to strategic planning, reflection and preventive overcoming than women $(\mathrm{p} \leq 0.05)$. Perhaps this is in line with the public opinion: men are considered to be better strategists who can assess all risks in advance and take the necessary preventive measures, and women prefer to act in a situation. It has been shown that for professionally healthy at all levels of specialists, high indicators of all three aspects of anticipatory ability are characteristic: they are well anticipating changes in space, time and communications with others, avoiding stressors and using the available opportunities in a timely manner ${ }^{4}$.

It was found that pro-active behavior indicators are more positively correlated $(p \leq 0,01)$ with indicators of all three levels of occupational health, except for indicators of "Search tool support" and "Search for

\footnotetext{
${ }^{4}$ Sheviakov O.V., Shramko I.A. Psychological provision of activities of professionals in the conditions of metallurgical production. Modern researches in psychology and pedgogy: collective monograph. Riga: Izdevniciba "Baltija Publishing". 2020. P. 405-420.
} 
emotional support". Search support from the outside, in turn, is inherent in infantile, self-sufficient specialists. In other aspects, the findings are consistent with numerous studies of proactive behavior.

It is found out that positive and rather high self-esteem of the experts of the economic sphere will be my physical and mental health is rather an indicator of their subjective well-being than the objective state of health. The lack or lack of competence in the field of management of their health is a potential limitation in the activities of specialists in the economic sphere.

Moreover, self-preservation of health implies not only the awareness of the need to constantly fight for it, but also the confidence in their capabilities on this path. The latter means that the specialist must be able to "decipher" his mental state and influence it, know his most powerful and weak individual-typological features, be able to impartially, adequately assess the level of his physical and mental capabilities.

\section{System program-targeted project of formation and preservation of professional health of specialists of economic sphere}

The system program-target project of formation and preservation of professional health of the specialists of the economic sphere is proposed and the results of the formation stage of the research are presented.

Within the framework of the system program-specific project of the formation and preservation of professional health of the specialists of the economic sphere, the "Model of Strategic Prevention of Professional Health of Specialists in the Economic Sphere" was proposed, which consisted of 5 stages: diagnosis, capacity, planning, implementation and evaluation.

The diagnosis included the process of collecting and analyzing information about the needs and resources of specialists in the economic sphere in order to get an idea of the scale and context of the problem of professional health. This information should be collected using both quantitative and qualitative methods, and include archival statistics. The assessment informs about planning and decision-making on prevention, the basics of developing the model and the need for changes in the selection of health-care programs, policies on professional health professionals in the economic sphere.

After completing the diagnosis of professional health professionals of the economic sphere, measures are required to develop and implement an integrated plan for solving socio-psychological problems of specialists at the level of the entire organization. This applies to such aspects as: corporate development and rallying of specialists; development of high organizational culture and "healthy" atmosphere in the team; professional and administrative support; effective leadership, adequate to the level (stage) of organizational development of the company and personnel; standards of 
formal and informal behavior in the organization; corporate loyalty and career growth of specialists; fair company career policy, no discrimination based on nationality/race, gender, age; clear and transparent (fair) system of fines and incentives; clarity of official duties and legitimacy of power.

The main tasks of socio-psychological support for the formation and preservation of professional health professionals of the economic sphere: psycho-emotional unloading; psychocorrection of personality deformations acquired as a result of burnout; learning "healthy coping" - constructive models of behavior of resistance; development of managerial skills (expansion of repertoire of managerial actions and strategies): increase of communicative competence, sensitivity (empathy) and communicative skills; development of relaxation skills, self-regulation and self-control; formation of positive and active living installations; development of creative potential; activation of the motivation of self-actualization and personal growth; planning personal and professional careers; Individual counseling on healthy lifestyles; creating an adaptive professional environment.

Within the framework of the programmatic and target-oriented project, a model is proposed for the formation of socio-psychological foundations for the formation and preservation of professional health professionals of the economic sphere.

The main directions of the process of social and psychological support of professional health of the specialists of the economic sphere are singled out: increasing the competence in the field of health, strengthening the reserve capacity of specialists and developing healthy behavior skills; prevention of dysfunction, or reduction of sources of professional stress. In practice, the implementation of these areas provided for the use of the following types of social and psychological support to ensure the effective professional activity of specialists in the economic sphere:

1. Psychological education - assistance in mastering the psychological knowledge necessary for self-improvement, improving the psychological competence in the field of health (lectures, special literature, video and audio materials, etc.).

2. Psychological diagnostics - the study of individual psychological peculiarities of the specialists of the economic sphere, on the basis of which assistance in individualization of professional activity, increase its efficiency, as well as self-knowledge.

3. Psychological prevention - prevention of the emergence and development of destructive mental states in the professional activities of specialists in the economic sphere ("burnout", internal conflicts, etc.).

4. Psychological counseling - analysis of specific situations that arise in the process of professional activity, and help in choosing the most appropriate solution. 
5. Psychological training - a specially developed complex of psychotechnicians, exercises and games that help in the development of the necessary qualities and skills, which allows not only to acquire new knowledge, but also to develop skills and habits of a healthy lifestyle.

6. Psychological correction - assistance in correcting or correcting existing negative mental states or personality traits, distorting the professional health of specialists in the economic sphere.

It has been shown that preventive activities aimed at the formation and preservation of professional health professionals of the economic sphere should be carried out at three levels: the specialist, the production group and the organization as a whole, since the action of preventive programs should be directed not only to a separate specialist in the economic sphere, but also to groups, as well as the organization as a whole, in order to provide social support in the process of changing relationships and style of life.

The system programmatic target project included comprehensive health improvement programs that contained a combination of leading aspects of the formation of the professional health of future professionals in the economic sphere. In particular, for the students of the universities of the economic profile of vocational training, a training workshop on the optimization of lifestyle "Self-management of health" was developed. Applicants of higher economic education have become participants in seminars and seminars on the basis of a formula for healthy selfpreservation. Each session consisted of three modules: 1) diagnostics of the basic components of professional health, methods of control and self-regulation; 2) stress; support for the body and the psyche, overcoming the syndrome of chronic fatigue and emotional burnout; 3) practical self-management.

In the Institute of Master's and Postgraduate Education at the University of Banking, the NBU, since May 2011, facultative classes "Business and Health" were offered to undergraduate students (specialties in finance and credit, banking, accounting and auditing). A coaching format was chosen for conducting classes, which was based on the idea that higher education graduates already have the key knowledge and skills necessary to maintain their occupational health status.

The content of the elective has aroused interest and practical value, and since September 2013, the selective discipline "Professional Health Management" was introduced, the purpose of which was to train graduates to be not only consumers and purchasers of health, but their creator, through conscious actions of the formation of social and an economic motive for the preservation and strengthening of their health. Another important point is the choice of a systematic approach to health, which allows individuals to control not so much the hidden symptoms of the disease, how to be able to 
assess the reserves of health reserves and be able to adapt to existing loads and conditions. At the trainings of higher education students, using exclusive information on professional health, the newest original diagnostic, adjusting and health-improving technologies, learned to independently develop comprehensive health improvement programs taking into account personal health, target-based prophylactic complexes for the locomotor system, vision, psycho-emotional states.

The ideology of the proposed health-saving programs contributed to the active and interested in mastering the methods of maintaining work capacity and resource status in the workplace, taking health-improving massage and self-massage, and auto-training. The self-monitoring module for objective and subjective health indicators provided an effective algorithm for the assimilation and subsequent use of positive healthy thinking - positive healthy emotions - positive healthy behaviors - positive healthy skills.

The analysis of the results of the diagnosis of the level of subjective control (according to J. Rotter) showed that the ratio of introversion and extraversion from respondents approached to a balanced one. This is one of the indicators of an adequate attitude to the problem of formation of professional health and responsibility for its preservation. With regard to personal qualities such as neuroticism and psychosis, they decreased by $42 \%$ and $55 \%$ respectively. Self-confidence increased 1.5-2 times, and in some cases 3 times. Respondents noted an increase in motivation for the formation of professional health, a willingness to intensify the acquired skills of managing their psycho-emotional and physical condition, professional self-preservation. Implementation of health practices on health management gives a positive dynamics of results. Future experts in the economic sphere become more energetic and full of enthusiasm, it becomes easier for them to cope with stress and internal tension. The moral climate in the team improves, the relationship in it; the number of occupations is significantly reduced.

Note that the analysis of the diagnostic testing of personnel and monitoring their activities during the working day allowed to conclude that more than $80 \%$ of specialists in the economic sphere organized the work process from the standpoint of healthcare-saving approach. On the basis of the analysis of data of medical examination and psycho-physiological examination of specialists of the economic sphere, there is a positive dynamics of reduction of diseases, increase of productivity of activity; the cost of medical care is significantly reduced.

This becomes a particularly significant trend in the current conditions of development of the Ukrainian economy, which requires the effective implementation of the latest educational and recreational technologies, the success of which, in turn, is largely determined by the willingness of 
business space participants to operate in a continuous innovation regime, engagement in flexible, prompt response to the changing needs of modern societies.

It should be noted that health management in the workplace is more effective than traditional activities such as visiting fitness centers, swimming pools or expanded health insurance. The peculiarity of organizational health programs lies in the fact that all the knowledge and skills acquired can be used by specialists on their own and do not require significant additional costs.

In general, the implementation of the system program-target project for the formation and preservation of professional health professionals of the economic sphere has allowed: to increase the loyalty of specialists of the economic profile to organizations; to make more effective corporate governance; improve the company's image; build motivation for health and healthy lifestyles; to discover the hidden potential of each specialist; increase productivity; Improve the psycho-emotional climate of the team; to optimize the level of self-actualization of employees; to form a group of like-minded people, oriented on mutual understanding and interaction, which has a significant impact on the quality of life and professional health of specialists in the economic sphere.

The scientific novelty of the study is that:

- for the first time in the national psychology the definition of the structure of occupational health in the measurement of economic activity as an independent phenomenological branch and subject of special analysis was made; the author's theoretical and methodological approach to the study of the process of occupational health of specialists in the economic sphere was implemented, which made it possible to identify their professionally important characteristics and to predict their transformations in changing social conditions; the conceptual model of professional health of specialists of the economic sphere is developed and it is established that the processes of its formation and preservation appear in dynamics, based on natural science and humanitarian paradigms, connected with peculiarities of perception of social situation and its possible (both positive and negative) consequences for professionals and determined by the specificity of their activities, the nature of relationships in the microsocial environment, attitude to occupational health; the stages of the processes of formation and preservation of occupational health of specialists in the economic sphere (stage of "initial formation" and "uncertain" attitude to occupational health; personal-activity stage (realization of social status of occupational health at the level of the professional community);

- ethical stage (value attitude to the profession and occupational health in general); types of value attitude to the professional activity and peculiarities of 
their manifestations in the economic sphere with different to with professional awareness (neutral (dominated by the criterion of uncertainty in the perception of lifestyle); pragmatic-realistic (with pragmatic and realistic criteria for attitude to life and future profession), value (with the needs of personal and professional self-realization, value, and value); the system program-targeted project of formation and preservation of professional health of specialists of economic sphere was introduced and the basic conditions for its effective realization were determined;

- deepened understanding of the socio-psychological nature and peculiarities of occupational health of the individual, his/her types, components and criteria, in particular in the specialists of economic sphere of activity; fundamental differences and essential specific properties, stages and regularities of the dynamics of the formation and preservation of their professional health;

- have further developed: methodological support for the study of the phenomenon of occupational health of the individual; approaches to the means and technologies of social and psychological influence on the processes of its formation and preservation of specialists of economic sphere of activity at different stages of their professionalization.

The theoretical significance of the study is to create a conceptual model of a healthy specialist in the field of economics, which is based on the theoretical two-level model of the categorical and conceptual apparatus of human science G. Ball (the position of rationalistic humanistic orientation in the methodology of human science) Diltz); identifying significant differences in the professional health of economic professionals; distinguishing its types and clarifying the specifics of the process of formation and development of occupational health as a holistic cognitive-motivational education in the form of a system of key social constructs of the specialist, related to adaptation, orientation, structuring, goals, existence; identifying the role of the occupational health crisis and its impact on the professional development of the specialist; disclosure of the dynamics of the occupational health of specialists in the economic sphere, connected with the activation of changes of the internal and external environment of the subject of professional activity; determining the socio-psychological factors of influence (age, position, professional experience, creative realization, etc.) on the economic specialist's view of the dynamics of their own occupational health.

The practical significance of the study is determined by the fact that the results of the study can find their application in various fields of social practice: in the economic sphere, education, production, management. The results of the dissertation research can be used to improve and enhance the effective adaptation of professionals to the requirements of the socioeconomic environment and its transformational changes in order to maintain their professional health. 
The data of the conducted research are used in the educational process in teaching vocationally-oriented disciplines and special courses in social psychology, psychology of social work, economic psychology, psychology of work, psychology of personality.

In addition, the theoretical provisions and results of the experiment will be useful in the process of training and practical activity of specialists in the economic field with the aim of improving the process of their thorough professional training and retraining; psychologists, managers and entrepreneurs in the direction of optimizing the formation of professional identity related to the values of their professionalism; applicants for higher education in economics. Theoretical and empirical results of the study on occupational psychology are included in the content of lectures and practical classes of the block of social and humanitarian disciplines "Life Safety", "Occupational Health", "Health Psychology", "Business Psychology", "Professional Development Psychology", "Conflictology", "Physical Education", "Innovative Technologies in Education", "Time Management and Business Communication", "Leadership and Team Building".

Theoretical and methodological analysis and generalization of scientific approaches to the problem of studying the professional health of the individual are carried out. The main directions of professional health research, which are mostly pragmatic in nature, consist in the development and implementation of programs to strengthen it, and to eliminate the negative effects of stress in the workplace.

It is shown that the programs of strengthening the professional health of the specialists of the economic sphere are aimed at achieving the goals of the prevention of the phenomenon of "burnout"; increase of productivity of activity due to improvement of physical and mental condition of specialists, improvement of moral and psychological climate in a team and others like that. In both foreign and domestic practice, the diversity of approaches to strengthening professional health professionals in the economic sphere is to develop health management programs, stress management and includes information and diagnostic and rehabilitation and prevention modules. It should be noted that a significant place in the programs of health management occupy medical issues. Socio-psychological aspects of professional health professionals in the economic sphere are only partially considered in programs of stress management and in programs for improving wellness. The aforementioned articulates the need to develop a conceptual model of professional health professionals of the economic sphere, which will solve issues related to its formation and preservation at different stages of the professionalization of these specialists.

It was determined that the professional health of specialists of the economic sphere is an integral characteristic of the functional state of the 
organism in terms of physical and mental parameters: an assessment of the ability to work, resistance to the adverse factors that accompany this activity. The main indicator of professional health professionals is ability to work, which reflects the indicated capabilities of a specialist and is defined as the maximum possible effectiveness of his professional activity, is determined by the functional state of the organism and takes into account its physiological value and consists of three groups of factors: physical status, psychological status and socio-psychological characteristic.

\section{CONCLUSIONS}

The socio-psychological specificity of the research of professional health specialists of the economic sphere was revealed, which was to determine the socio-psychological factors of their professional health, such as: determining the place of professional health in the system of values of specialists; study of the structure of stress factors in their professional activities; Identification of the relationship of individual psychological characteristics and specifics of professional health professionals; Identify the main strategies and ways to overcome stress situations in professional activities; formation of professional qualities that will support the support of professional health professionals of the economic sphere; achievement of the optimal ratio of energy (personal) costs and achieved results in the course of professional training ("effectiveness/resources"). The optimization of this process was seen in the need to take into account the typology of competence of a specialist in the economic sphere, namely: learning to know (vocational and methodological competence); learning to live together (social and communicative competence); learning to do (competence in the activity aspect, implementation of plans in life); learning to be (competence in the personal aspect).

The system program-target project for the formation and preservation of professional health professionals of the economic sphere at various stages of their professionalization based on the strategies of the system approach, the social cognitive theory, the model of behavioral potential and the constructivist socio-psychological approach during its realization is developed and implemented.

System program-target project for the formation and preservation of professional health of specialists of the economic sphere allowed to solve the problem of increasing the professional and creative activity of specialists; contributed to the development of the socio-psychological competence of specialists in the formation and preservation of their professional health; to influence group self-awareness in the direction of maintaining and maintaining professional health; effective use of various forms of moral encouragement; the formation of a favorable socio-psychological climate, etc. 
The main components of the effective implementation of the project are the formation of professional health, taking into account active social and psychological methods of training and assistance; carrying out of measures in the direction of professional self-realization of specialists of the economic sphere, in particular, vocational guidance competitions; creation and development of services of psychological support and assistance to the specialists of the economic sphere; motivation and stimulation of the specialists of the economic sphere for productive work; implementation of preventive and motivational training aimed at developing the competence of specialists in the field of professional health formation, raising the level of professional self-awareness; assimilation of effective forms of work (selfdisclosure, self-expression, self-knowledge, empathy, development of sanogeneous thinking and reflection, the need for relaxation); the formation of effective skills for maintaining health in the workplace and setting up a healthy lifestyle.

In the prospect of research, we see the definition of the characteristics of professional health professionals of other fields of activity, as well as the study of the process of becoming a professional health at different age stages of life personality (maturity, late maturity, in old age). The in-depth study and the problem of attracting and training psychologists, teachers, and managers to participate in the process of formation and preservation of professional health of the individual in various spheres of his activity is in need of in-depth study. It is urgent to further develop socio-psychological trainings and correctional systems that will promote the prevention of negative manifestations associated with professional destructions of specialists, as well as their professional health.

\section{SUMMARY}

The purpose of the article is to find a new solution to the problem of creating psychosocial foundations of occupational health of economic specialists from the standpoint of behavioral economics. Methodical principles of formation and development of professional health of specialists are distinguished: stages, regularities, dynamics. The psychosocial specificity of research and the levels of formation and preservation of health of specialists in the economic sphere are revealed. The essence, types, components and criteria of labor protection of specialists of economic sphere are determined. The conceptual model of formation and preservation of health of specialists of the economic sphere is offered, which is implemented as a theoretical and methodological strategy of a systematic and holistic process of ensuring the achievement of the result of professional activity. New ideas about a healthy person who responsibly manages his own health and realizes himself in society, the image of a specialist who independently 
sets the goals of formation and preservation of occupational health, chooses the best ways and means of their achievement.

\section{REFERENCES}

1. Blynova O.Y., Holovkova L.S., Sheviakov O.V. Philosophical and sjciocultural dimensions of personality psychological security. Antropological Measurements of Philosophical Research. 2018. Issue 14. P. 73-83. DOI: 10.15802/ampr.v0i14.150758

2. Psychologycal Provision of Processes Modernization of Metallurgical Production Management / N. Yevdokymova at al. International Journal of Recent Technology and Engineering. 2019. Issue 8 (4S). P. 115-121. DOI: 10.35940/ijrte. D1004.1184519

3. Golovkova L.S., Sheviakov A.V., Golovkova A.E. Psychological provision of professional health of specialists of economic sphere. Review of transport economics and management. Issue 2 (18). P. 90-99. DOI: $10.15802 /$ rtem.v18i2.190130

4. Sheviakov O.V., Shramko I.A. Psychological provision of activities of professionals in the conditions of metallurgical production. Modern researches in psychology and pedgogy : Collective monograph. Riga : Izdevniciba "Baltija Publishing", 2020. P. 405-420. DOI: 10.30525/ 978-9934-588-36-5/23

\section{Information about the autors:}

Burlakova I. A.,

Doctor of Psychological Sciences, Associate Professor, Professor at the Department of Practical Psychology and Social Work East-Ukrainian National University named after Volodymyr Dahl 59-A, Centralny str., Severodonetsk, 93406, Ukraine

Sheviakov O. V.,

Doctor of Psychological Sciences, Professor, Head of the Department of General Psychology

Private Higher Education Establishmeht

"Dnipro Humanitarian University"

35, Yermolova str., Dnipro, 49000, Ukraine 